\title{
TURISMO RURAL EN CATALUÑA: CONDICIONANTES DE LA OFERTA Y LA DEMANDA
}

\author{
Gemma Cànoves, Luis Herrera y Lucia Cuesta ${ }^{1}$ \\ Departamento de Geografía \\ Universidad Autónoma de Barcelona
}

\begin{abstract}
RESUMEN
El artículo presenta la distribución territorial del turismo rural en Cataluña teniendo en cuenta factores condicionantes de la oferta y la demanda. El análisis permite apuntar un patrón de distribución territorial de los establecimientos de turismo rural. En primer lugar, se identifica la localización de los diferentes tipos de alojamientos (Masies, Cases de Poble y Alojamientos Rurales Independientes), a la vez que se realiza un análisis de la oferta y la demanda del turismo rural. Sobre esta premisa se examinan los posibles factores que afectan a la localización y su grado de influencia sobre la demanda. Se trata de factores interrelacionados, entre los que destacan la existencia de explotaciones agrarias, casas con especial valor patrimonial y paisajes naturales atractivos. En el último apartado, relacionamos el comportamiento del turismo rural con el de sol y playa y se concluye con la constatación de la existencia de patrones de demanda comparables y similitudes en la estacionalidad y estancia media, así como diferencias considerables en la proporción de turistas extranjeros.
\end{abstract}

Palabras clave: turismo rural, distribución territorial, oferta, demanda, Cataluña.

\begin{abstract}
This article presents the spatial distribution of rural tourism in Catalonia considering the conditioning factors of supply and demand. This analysis makes possible to observe the existence of a pattern of distribution of these accommodations. Initially there is an identification of the distribution of the different types of accommodation (Masies, Village Houses and Independent Rural Accommodations), and at the same time we offer an analysis of supply and demand of rural tourism. On this basis, we have examined the possible factors that affect localization and its degree of influence on demand. In the case where
\end{abstract}

1 Este artículo recoge parte de las investigaciones llevadas a cabo por los autores dentro de los proyectos: «Desarrollo turístico rural y revalorización sociocultural y mediambiental en Cataluña, Galicia y Baleares» DGES (2000-2003) y «El turisme rural a Catalunya: una aposta mediambiental i de qualitat». Fundació Abertis (2004). (http://seneca.uab.es/ter). Una versión reducida de las investigaciones se presentó en el IX Coloquio de Geografía del Turismo, Ocio y Recreación, Zaragoza, 2004. 
multiple factors are interrelated, we can emphasize the existence of farming combined by appropriated homes and attractive and natural landscapes. In the last section we relate rural tourism with $3 \mathrm{~S}$ tourism market and we conclude that there are comparable demand patterns and some similarities in aspects like the seasonal patterns as well as the average length of stay, just as there are considerable differences in the proportional number of foreign tourists.

Key words: rural tourism, supply, demand, Catalonia.

\section{Introducción}

El turismo rural en Cataluña - como en otras regiones - se ha desarrollado de forma espontánea y fragmentada (Cànoves et al, 2002: 90-103; Cànoves, et al, 2004a: 755-769; Barke, 2004: 137-149; Yagüe, 2002:1101-1110). Este turismo no se ha distribuido uniformemente por el territorio. Dicha distribución podría ser simplemente casual, dependiendo del juicio, la iniciativa o la estrategia empresarial de los agricultores. Sin embargo, este artículo pretende demostrar que el patrón resultante refleja la interacción de una serie de factores, la mayor parte de los cuales son geográficos. Para ello, y con el objetivo de establecer los condicionantes de la oferta y la demanda en el turismo rural, se ha estudiado tanto la demanda como la oferta desde la perspectiva de factores espacialmente diferenciados. De ahí que, tras analizar la distribución de los diferentes tipos de alojamientos, identificar los flujos de turistas y los patrones estaciónales de la demanda, el artículo analiza los posibles factores que los condicionan. Posteriormente se pretende establecer cómo condicionan estos factores a la localización de los establecimientos y la influencia que ejercen sobre la demanda.

\section{Metodología}

Los resultados que se exponen en el artículo son una pequeña parte de un estudio más amplio sobre la evolución y situación del turismo rural en Cataluña ${ }^{2}$. El estudio combina metodología cualitativa y cuantitativa con el objetivo de reunir el máximo de información que permitiera explicar la situación del turismo rural en Cataluña. Las fuentes estadísticas que se han trabajado nos han permitido tener un amplio marco de referencia sobre el turismo rural en Cataluña y poderlo comparar con la situación en España. Hemos utilizado, entre otros, la encuesta mensual de ocupación de establecimientos turísticos del Instituto Nacional de Estadística (INE); los resúmenes anuales que este organismo elabora han sido una fuente básica de información. Deben destacarse también, los datos de turismo obtenidos a partir del Instituto de Estadística de Cataluña (IDESCAT). Otras fuentes de interés han sido los estudios realizados por la Dirección General de Turismo de la Generalitat de Catalunya (DGT) y por el Instituto de Estudios Turísticos (IET) de la Secretaría de Estado Comercio y Turismo del Ministerio de Industria, Comercio y Turismo. El censo de las casas de turismo rural se elaboró a partir de la «Guia d'Establiments de Turisme Rural de la Generalitat de Catalunya» del 2003 y con la visita y contactos a las Asociaciones o Federaciones de Turismo Rural existentes en Cataluña. En total obtuvimos 758 propietarios de casas de turismo rural. A partir de esta base se envió un cuestionario a los propietarios (abril de 2003 mayo de

2 «Turismo rural en Cataluña: una apuesta medioambiental y de calidad» Fundació Abertis, 2004. (http://seneca.uab.es/ter) 
2004) y obtuvimos 274 encuestas contestadas (un $37 \%$ de la muestra). De esta muestra seleccionamos 50 casas (con una distribución territorial homogénea) a las que enviamos un cuestionario a fin de que lo respondieran los usuarios. Se enviaron 30 cuestionarios por casa, lo que suponía un total de 1500. Las respuestas fueron 404 (el 26,9\% de la muestra). Paralelamente se realizaron 22 entrevistas en profundidad que se hicieron a las casas que nos habían respondido que estaban dispuestas a un segundo contacto y que eran diversas en las tipologías de turismo rural y presentaban actividades innovadoras que nos permitían ver hacia donde se encaminaba el sector. Estas entrevistas han sido de gran valor, ya que nos muestran las opiniones de los propietarios, las preocupaciones, las motivaciones y perspectivas de futuro del turismo rural. Finalmente se trataron los datos a nivel estadístico, se codificaron las entrevistas en profundidad y se cartografiaron los resultados. Este material, junto con las estadísticas oficiales es la base de la investigación y del presente artículo.

\section{La oferta de turismo rural}

La modalidad de turismo rural en Cataluña es reciente y en los últimos diez años ha experimentado un crecimiento importante (gráfico 1). La legislación sobre turismo rural apareció en Cataluña en 1983, siendo la primera Comunidad Autónoma en legislar sobre esta materia. (Cànoves et al, 2000: 51-77). De este modo, se reconocía y regulaba la existencia del sector.

GRÁFICO 1. Evolución del turismo rural en Cataluña, 1986-2003.

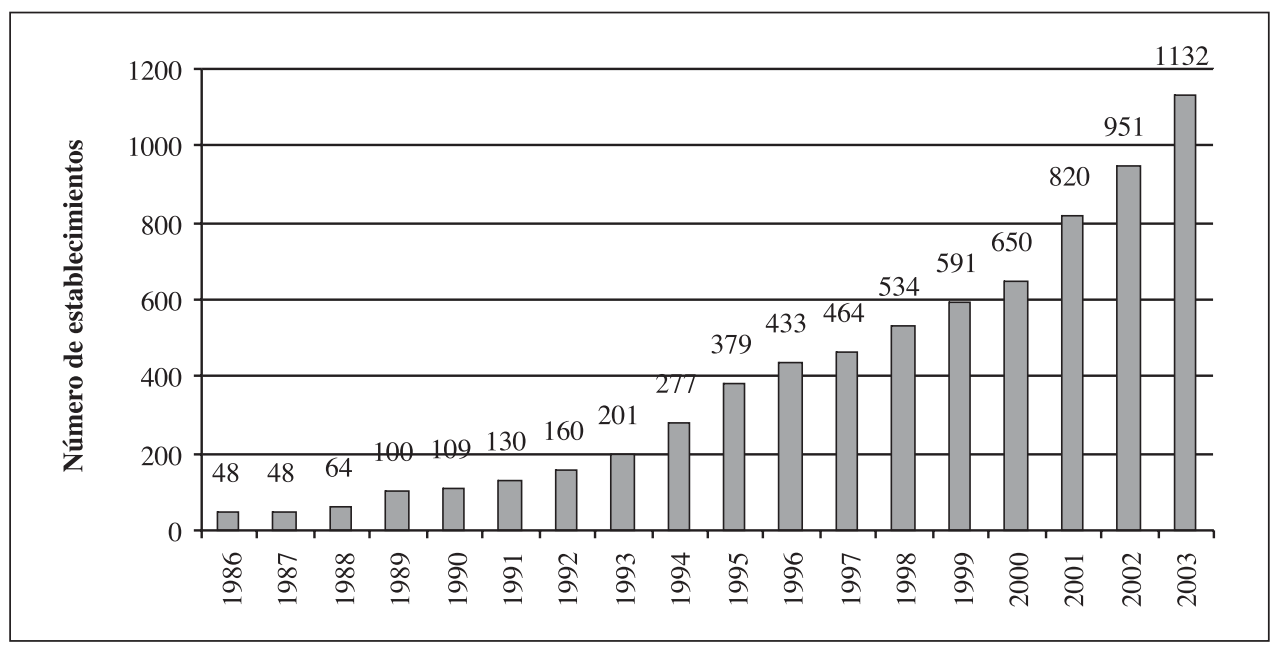

Fuente: Direcció General de Turisme, 2004.

En los inicios la denominación y modalidad de turismo rural era la denominada «Residencies cases de pagès». Doce años más tarde, se introdujeron tres tipologías claramente diferenciadas (Decreto 214/1995): «Masia» (casa aislada), «Casa de Poble» (casa en un pequeño pueblo de no más de mil habitantes) y «Alojamiento Rural Independiente» (ARI) (alquiler de una casa, que puede situarse en un paraje aislado o en pequeños pueblos). Las principales diferencias entre «Masia» $\mathrm{y}$ «Casa de Poble» $\mathrm{y}$ «Alojamiento Rural Independiente» es que en las dos primeras el propietario convive con los huéspedes, a los que alqui- 
la habitaciones de su vivienda, y ha de obtener parte de sus ingresos del sector primario. Mientras en los ARIS, el propietario se limita al alquiler de una vivienda. En el 2002, se introdujeron nuevas modificaciones (Ley 13/2002 de 21 de junio) para establecer una distinción básica. Las casas que perciben parte de sus ingresos de las actividades agrarias y mantienen el binomio actividad agraria-turismo y que se denominan «Casas de Pagès» y aquellas casas que se alquilan pero que no tienen actividad agrícola y que se mantienen con la denominación de «Alojamiento Rural». Estas distinciones serán aplicadas en la creación de nuevas tipologías pero por el momento se mantienen las enunciadas por el Decreto 214/1995 (Masia, Casa de Poble y ARI), que han sido la tipología que hemos estudiado (Tabla 1).

En Cataluña, existen 1107 alojamientos de turismo rural (octubre de 2003) distribuidos, a primera vista, de forma heterogénea en el territorio (figura 1). Un análisis detallado nos muestra marcadas concentraciones de cada una de las diferentes tipologías (figuras 2,3 y 4). Así, la Región Metropolitana de Barcelona, la zona más densamente poblada con cuatro millones de habitantes, dispone de escasos alojamientos de turismo rural. De la misma forma, encontramos pocos establecimientos situados cerca de la costa. La explicación de esta reducida concentración se explica, en parte, por la escasa actividad agrícola y de espacios atractivos para el turismo rural, junto con la oferta predominante de turismo litoral. De todas formas, las áreas de influencia de las principales de destinaciones costeras - Costa Brava y Costa Dorada - están bien dotadas de alojamientos rurales. Ambas zonas presentan una importante tradición de turismo litoral y a su vez un aumento de los alojamientos de turismo rural en sus territorios interiores o tras país. El norte de Cataluña, que coincide con los Pirineos y Pre-Pirineos, constituye otra de las principales zonas de concentración de alojamientos y ello se explica por presentar importantes atractivos naturales altamente valorados por los usuarios del turismo rural.

TABLa 1. Principales características de los actuales tipos de turismo rural, 2003.

\begin{tabular}{|c|c|c|c|}
\hline & ARIs & Masies & Cases de Poble \\
\hline Actividad agroturística & Opcional & \multicolumn{2}{|c|}{$\mathrm{Si}$, normalmente se ofrece a petición del cliente } \\
\hline Alquile de habitaciones & No & \multicolumn{2}{|c|}{$\mathrm{Si}$} \\
\hline Alquiler de casa completa & $\mathrm{Si}$ & \multicolumn{2}{|c|}{ No } \\
\hline Convivencia con propietario & No & \multicolumn{2}{|c|}{$\mathrm{Si}$} \\
\hline Plazas & $4-15$ & \multicolumn{2}{|c|}{$5-15$} \\
\hline Ubicación & $\begin{array}{l}\text { Tanto en núcleos } \\
\text { de población de } \\
\text { menos de } 1.000 \\
\text { hab. como aislados }\end{array}$ & Aisladas & $\begin{array}{c}\text { Núcleos de población } \\
\text { de menos de } 1.000 \\
\text { habitantes }\end{array}$ \\
\hline Derecho a cocina & $\mathrm{Si}$ & \multicolumn{2}{|c|}{ Opcional } \\
\hline Servicios mínimos & Ninguno & \multicolumn{2}{|c|}{ Desayuno } \\
\hline $\begin{array}{l}\text { Requerimientos de } \\
\text { construcción mínimos }\end{array}$ & \multicolumn{3}{|c|}{ Construcción tradicional anterior a 1.950} \\
\hline Requerimientos propietarios & $\begin{array}{c}3 \text { años de } \\
\text { residencia mínima } \\
\text { en la comarca }\end{array}$ & \multicolumn{2}{|c|}{$\begin{array}{c}3 \text { años de residencia mínima en la casa que se } \\
\text { quiere legalizar }\end{array}$} \\
\hline $\mathrm{N}^{0}$ casas diciembre 2002 & 634 & 136 & 156 \\
\hline Proporción diciembre 2002 & $68,5 \%$ & $14,7 \%$ & $16,8 \%$ \\
\hline
\end{tabular}

Elaboración propia. 
FIGURA 1. Establecimientos de turismo rural por municipios, octubre 2003.

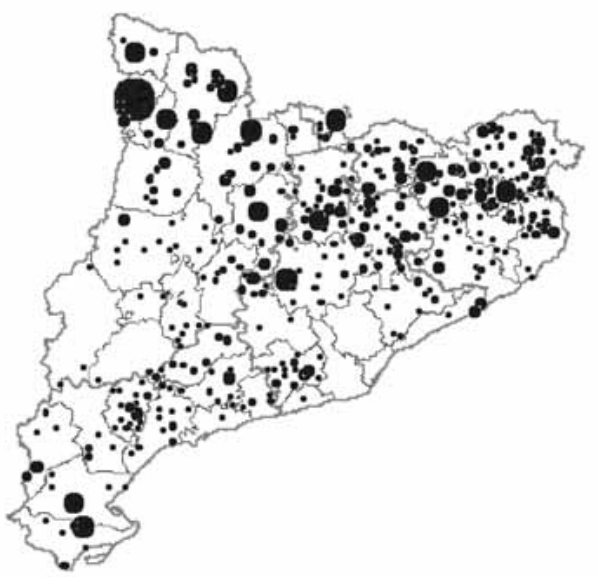

- Menos de 5

- $5-10$

- $11-20$

$21-30$

Más de 30

FigURA 2. ARIs por municipios, octubre 2003.

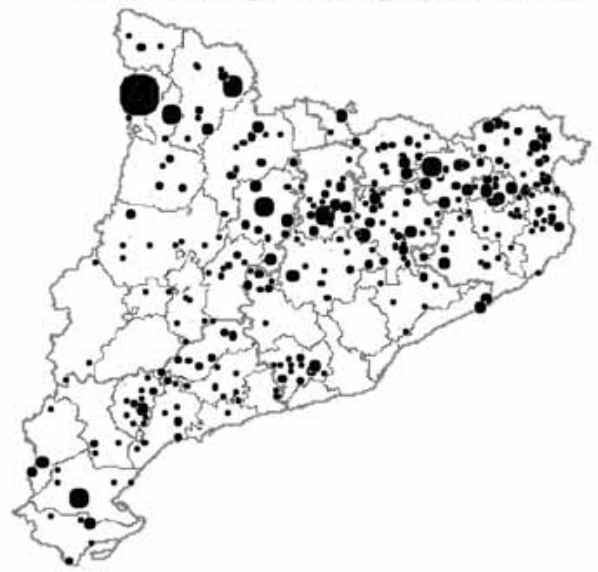

Figura 3. Cases de Poble por municipios, octubre 2003.

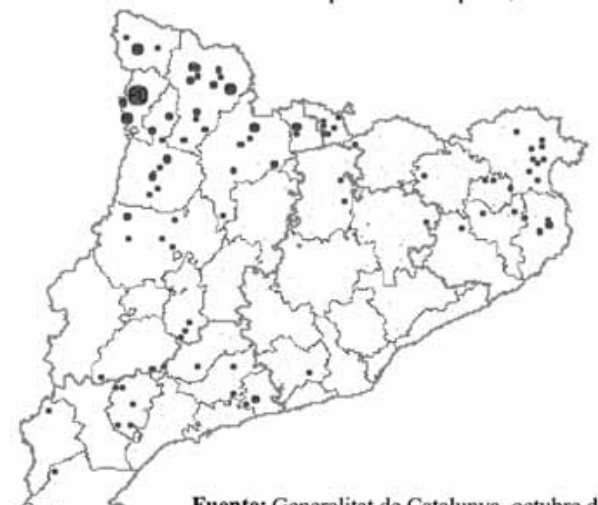

FIGURA 4. Masies por municipios, octubre 2003.

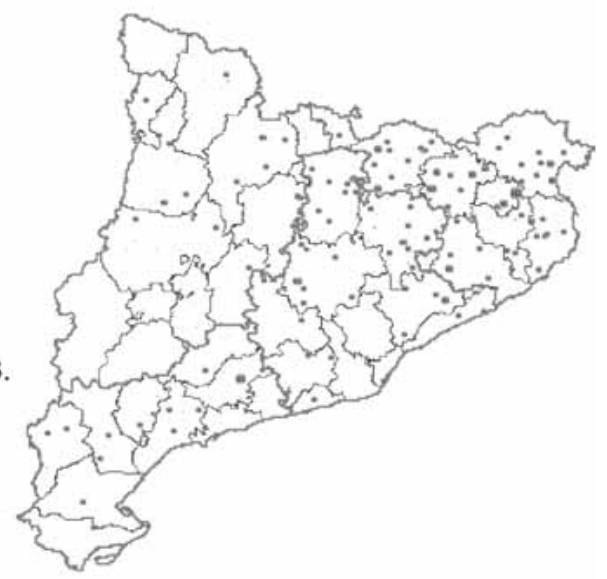


Un análisis de las diferentes tipologías nos muestra que el patrón de localización de los «ARIs» coincide ampliamente con el patrón general. Esto es normal puesto que son el tipo de alojamiento predominante (gráfico 2). Además, el hecho de que puedan estar localizados tanto en pueblos como en parajes aislados, y dado que los propietarios no han de dedicarse a actividades primarias, permite que la ubicación de esta categoría sea mucho más extensa y dispersa en el territorio (Cànoves, et al, 2004:111-128).

GRÁFICO 2. Proporción de tipos de establecimientos abiertos anualmente, 1995-2003.

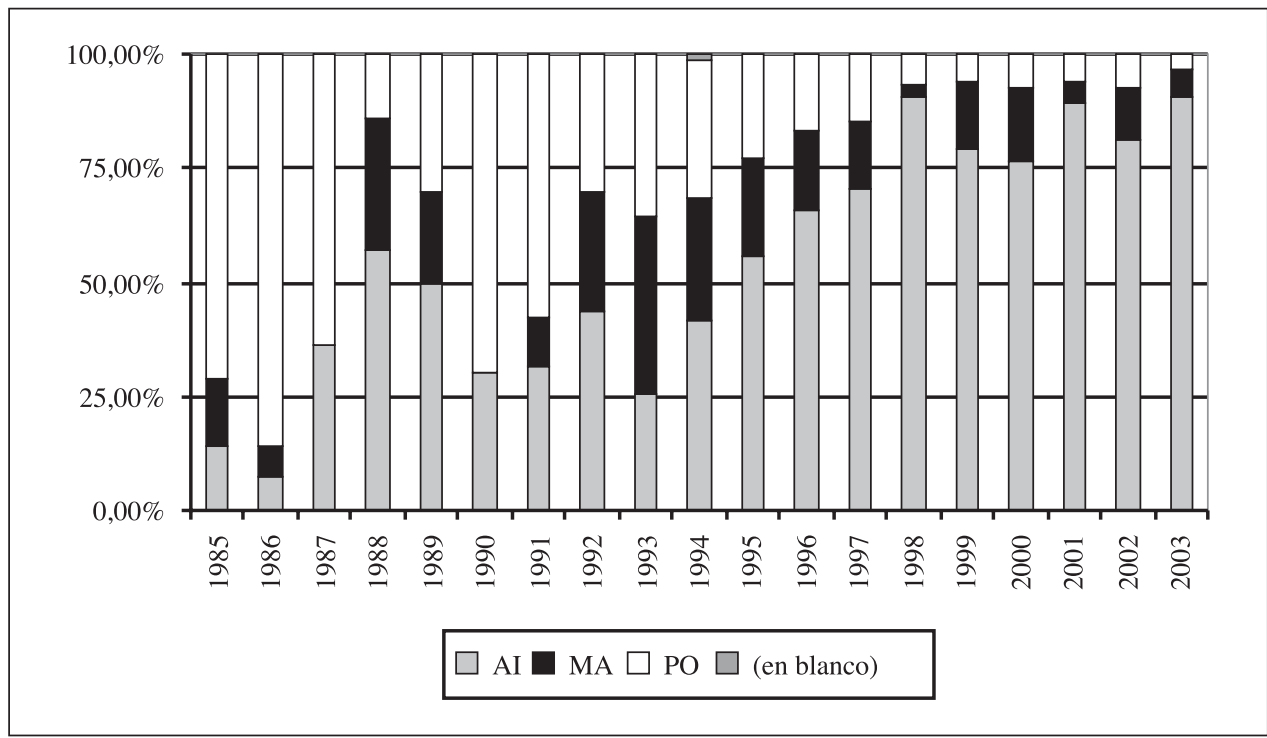

Fuente: Generalitat de Catalunya, 2004. Elaboración propia.

En el caso de las «Masies», la distribución está condicionada por las restricciones de antigüedad y características arquitectónicas. Las «Cases de Poble» se ven condicionadas, además, por el tamaño del pueblo. Ambas tipologías existen a lo largo de la geografía catalana pero destaca particularmente la existencia de «Masies» en el área que abarca desde los valles del Besòs-Congost-Ter hasta las planas del Empordà. Por el contrario, en la parte más occidental de los Pirineos (provincia de Lleida) la población rural tiende a concentrarse en pequeños pueblos, lo que permite la existencia de «Cases de Poble».

Podemos considerar fácil el acceso a la mayor parte de establecimientos para la población urbana catalana, ya que un $73 \%$ de estos se encuentran a no más de 25 kilómetros de una ciudad de más de 50.000 habitantes. Además, la distancia media que separa las Masies y los ARIs del núcleo más cercano es de tan sólo 3,5 kilómetros (tabla 2) (Generalitat de Catalunya, 2003).

Como resultado, los usuarios del turismo rural emplean entre 2-3 horas (y normalmente menos) para llegar a sus destinos (figura 5). Es en parte esta proximidad territorial lo que facilita el turismo rural de fin de semana. Así, podemos apuntar que en algunas zonas del Pirineo catalán el turismo rural viene a ser la alternativa ante la dificultad de tener una segunda residencia. 
TABLA 2. Distancia entre establecimientos de turismo rural y la ciudad más cercana de más de 50.000 habitantes, 2002-2003.

\begin{tabular}{|l|l|}
\hline Distancia $(\mathbf{k m})$ & \% del total \\
\hline$<\mathbf{5}$ & 3.65 \\
\hline $\mathbf{5}-\mathbf{1 0}$ & 10.95 \\
\hline $\mathbf{1 1 - 2 5}$ & 51.46 \\
\hline $\mathbf{2 5}$ & 27.01 \\
\hline $\mathbf{N s} / \mathbf{N c}$ & 6.93 \\
\hline
\end{tabular}

Fuente: Trabajo de campo. Elaboración propia.

FiguRA 5. Distancia en tiempo de Barcelona a las capitales municipales catalanas.

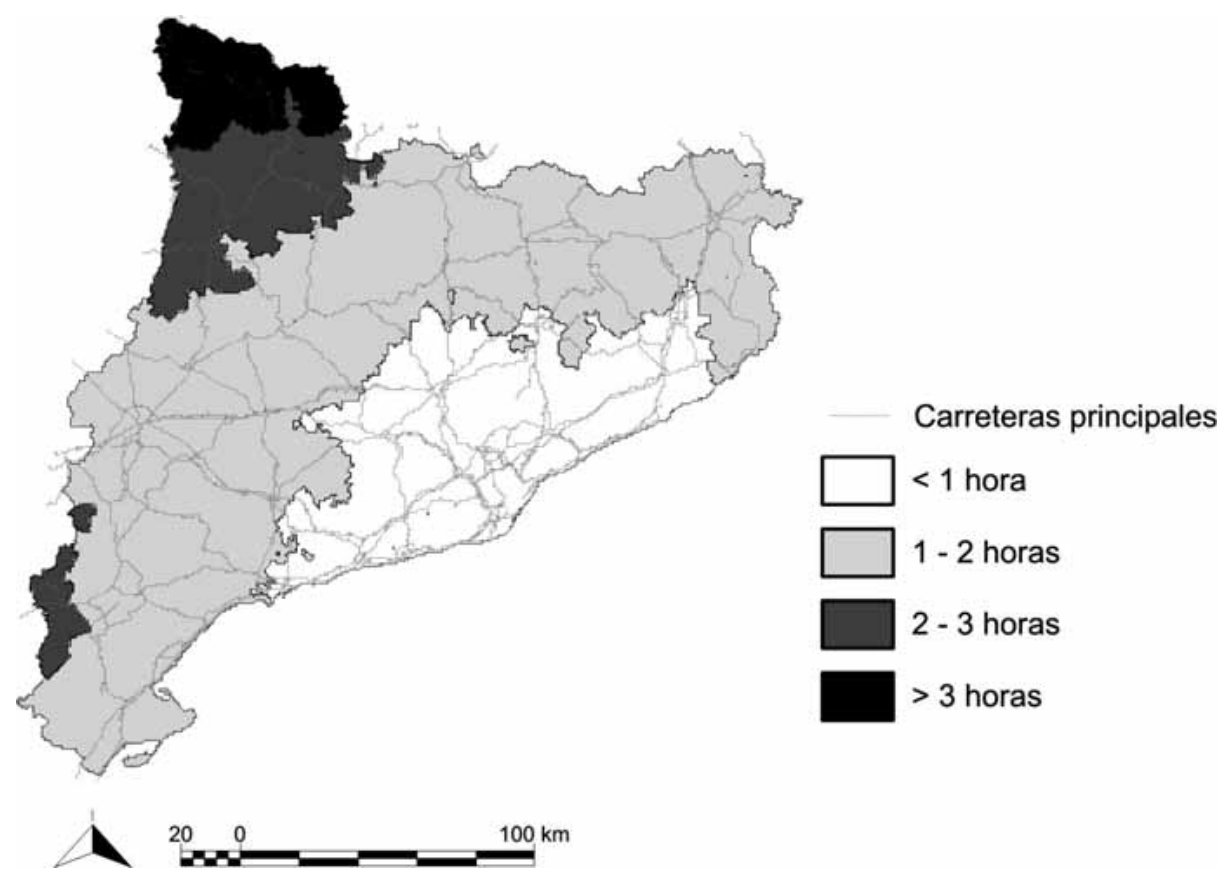

Elaboración propia. 


\section{Demanda de turismo rural}

El análisis de la demanda de alojamientos de turismo rural nos muestra que el número de visitantes en el 2002 fue de 164.156, de los cuales el 90\% eran españoles (INE, 2003b). Esta cifra representa únicamente el $0,7 \%$ del total del turismo catalán pero constituye casi el $12 \%$ de la demanda de turismo rural en España. Las pernoctaciones supusieron un total de 490.217, lo que representó el 0,32\% del total de Cataluña y la estancia media en un alojamiento de turismo rural fue de tres días (INE, 2003b).

De hecho, el número total de turistas rurales y sus correspondientes pernoctaciones creció considerablemente entre el 2001 y el 2002 (8,89\% y 6,60\% respectivamente), a pesar de que el número de viajes turísticos de los españoles decreció en un 5,5\% (IET, 2004). El incremento en el número de visitantes extranjeros es particularmente significativo (más de un $25 \%$ ), sobre todo en un periodo en el que el incremento del total de visitantes extranjeros en Cataluña fue de un 5,7\% (IET, 2004). De todas formas, hemos de ser cautos a la hora de interpretar estos datos dado que la cifra absoluta de la que partimos es muy pequeña. También hemos de tener en cuenta que el transporte aéreo experimentó una importante crisis como consecuencia de los ataques del 11 de septiembre de 2001. Crisis que favoreció, tanto los viajes por carretera como las destinaciones turísticas próximas y poco masificadas, y en parte al turismo rural.

TABLA 3. Visitantes de turismo rural en Cataluña, 2001-2002.

\begin{tabular}{|c|c|c|c|c|c|c|c|c|c|c|}
\hline \multirow[t]{3}{*}{ Origen } & \multicolumn{5}{|c|}{ Visitantes } & \multicolumn{5}{|c|}{ Pernoctaciones } \\
\hline & \multicolumn{2}{|l|}{2001} & \multicolumn{2}{|l|}{2002} & \multirow{2}{*}{\begin{tabular}{|l|} 
Cambio \\
2001-2
\end{tabular}} & \multicolumn{2}{|l|}{2001} & \multicolumn{2}{|l|}{2002} & \multirow{2}{*}{\begin{tabular}{|l} 
variación \\
$2001-2$
\end{tabular}} \\
\hline & Número & $\%$ & Número & $\%$ & & Número & $\%$ & Número & $\%$ & \\
\hline Total & 150,748 & 100 & 164,156 & 100 & $8.89 \%$ & 459,881 & 100 & 490,217 & 100 & $6.60 \%$ \\
\hline Españoles & 138,450 & 91.84 & 148,695 & 90.58 & $7.40 \%$ & 398,699 & 86.70 & 419,638 & 85.60 & $5.25 \%$ \\
\hline Estranjeros & 12,298 & 8.16 & 15,460 & 9.42 & $25.71 \%$ & 61,183 & 13.30 & 70,579 & 14.40 & $15.36 \%$ \\
\hline
\end{tabular}

Fuente: INE (2003a; 2003b).

$\mathrm{Al}$ analizar en detalle la demanda vemos que el patrón varía considerablemente. Según datos del INE (2003a; 2003b), del 90\% de usuarios/visitantes españoles, un 89,86\% eran catalanes, siendo la principal fuente de demanda la población del gran núcleo que constituye la Región Metropolitana de Barcelona (que cuenta con más de 4 millones de habitantes). También encontramos una pequeña proporción de clientes que provienen de otras zonas de España: un 3,42\% vienen de Madrid, un 2,27\% de Valencia y un 1,06\% de Euskadi. Restando el 3,39\% que se reparte entre las 13 restantes Comunidades. La conclusión más evidente a la vista de los datos es el fuerte componente de turismo local que muestra el turismo rural en Cataluña.

Si nos fijamos en los turistas extranjeros (tabla 4) constatamos que la gran mayoría $(85,86 \%)$ del 9,42\% proviene de la Unión Europea. De estos, un tercio son ingleses, el $17,46 \%$ franceses, el 14,70\% Neerlandeses y sólo un 6\% vienen de Bélgica y Alemania. El mayor contingente de turistas no europeos proviene de los Estados Unidos (4,80\%). A la vista de la tabla podemos deducir un ligero incremento del número de turistas y de las pernoctaciones, que confirma el afianzamiento de la afluencia de turistas rurales en Cataluña.

El análisis de la demanda mensual de turismo rural en Cataluña (tabla 5 y gráfico 3) muestra que los turistas tienden a fragmentar sus estancias a lo largo del año. Junto con las 
TABLA 4. Origen de los turistas rurales extranjeros en Cataluña, 2001-2002.

\begin{tabular}{|c|c|c|c|c|c|c|c|c|}
\hline \multirow[t]{2}{*}{ Origen } & \multicolumn{4}{|c|}{ Visitantes (\%) } & \multicolumn{4}{|c|}{ Pernoctaciones (\%) } \\
\hline & 2001 & $\%$ & 2002 & $\%$ & 2001 & $\%$ & 2002 & $\%$ \\
\hline UE (sin España) & 10.858 & 88,29 & 13.246 & 85,68 & 54.343 & 88,82 & 60.974 & 86,39 \\
\hline Alemania & 1.508 & 12,26 & 946 & 6,12 & 7.393 & 12,08 & 4.386 & 6,21 \\
\hline Bélgica & 896 & 7,29 & 1.015 & 6,57 & 6.492 & 10,61 & 6.631 & 9,40 \\
\hline Francia & 2.470 & 20,08 & 2.699 & 17,46 & 11.525 & 18,84 & 10.961 & 15,53 \\
\hline Países Bajos & 1.558 & 12,67 & 2.272 & 14,70 & 8.985 & 14,69 & 10.716 & 15,18 \\
\hline Reino Unido & 3.517 & 28,60 & 5.108 & 33,04 & 15.930 & 26,04 & 23.172 & 32,83 \\
\hline EEUU & 420 & 3,42 & 742 & 4,80 & 2.839 & 4,64 & 4.041 & 5,73 \\
\hline Otros países & 1.929 & 15,69 & 2.678 & 17,32 & 8.019 & 13,11 & 10.672 & 15,12 \\
\hline Total extranjer. & 12.298 & 100,00 & 15.460 & 100,00 & 61.183 & 100,00 & 70.579 & 100,00 \\
\hline
\end{tabular}

Fuente: INE (2003a; 2003b).

TABLA 5. Demanda del turismo rural en Cataluña, 2001-2002.

\begin{tabular}{|l|l|l|l|l|l|l|l|l|}
\hline \multirow{2}{*}{} & \multicolumn{4}{|c|}{ Visitantes } & \multicolumn{3}{c|}{ Pernoctaciones } \\
\cline { 2 - 9 } & \multicolumn{2}{|c|}{$\mathbf{2 0 0 1}$} & \multicolumn{2}{c|}{$\mathbf{2 0 0 2}$} & \multicolumn{2}{c|}{$\mathbf{2 0 0 1}$} & \multicolumn{2}{c|}{$\mathbf{2 0 0 2}$} \\
\cline { 2 - 9 } & Total & $\mathbf{\%}$ & Total & $\mathbf{\%}$ & Total & \% & Total & \% \\
\hline Total España & 1.210 .890 & 100 & $1.370,369$ & 100 & 3.660 .816 & 100 & 4.104 .680 & 100 \\
\hline Total Cataluña & 150.748 & $12,45^{*}$ & 164.156 & $11,98^{*}$ & 459.881 & $12,56^{*}$ & 490.217 & $11,94^{*}$ \\
\hline
\end{tabular}

* Porcentaje con respecto al total del turismo rural español.

Fuente: INE (2003a; 2003b).

GRÁFICo 3. Demanda mensual de turismo rural en Cataluña, 2001-2002.

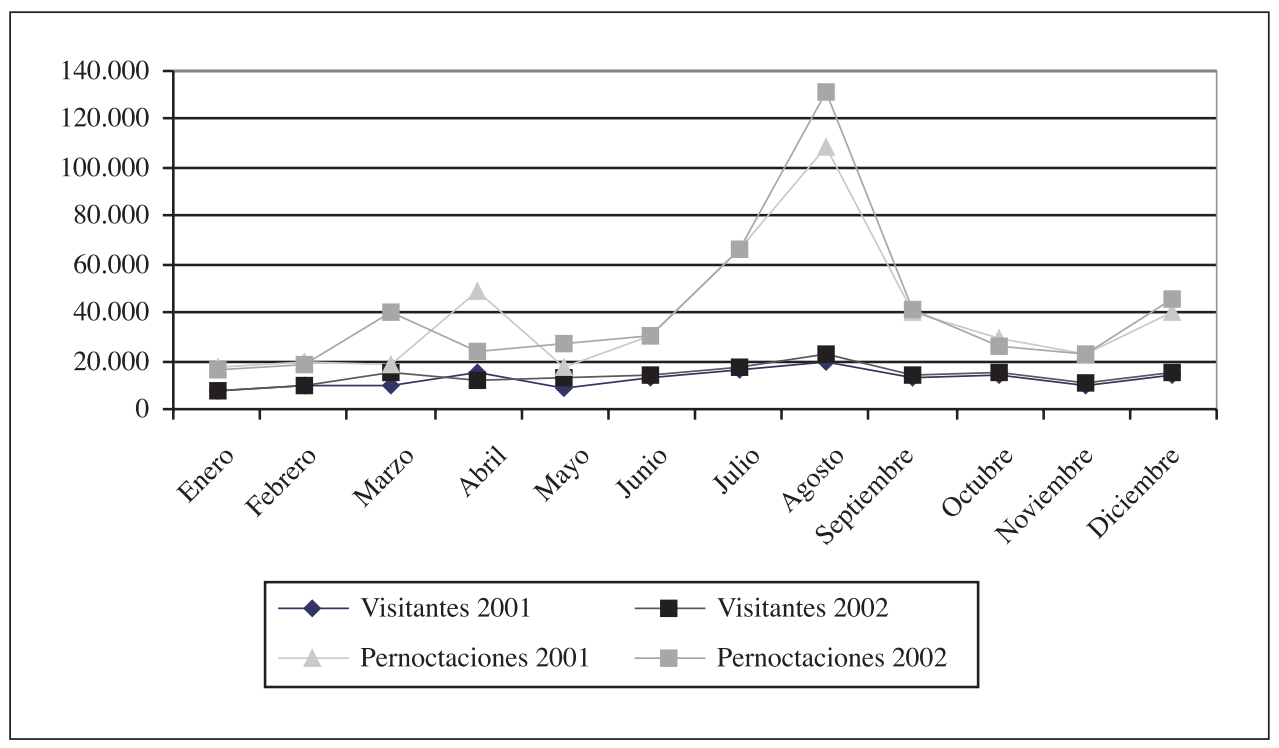

Fuente: INE (2003a; 2003b) 
tradicionales vacaciones estivales también aprovechan los fines de semana y puentes. De este modo, a excepción de enero (mes en el que la demanda es especialmente baja y algunos establecimientos cierran por vacaciones), el número de visitantes en agosto (mes de vacaciones por antonomasia) sólo dobla el de temporada baja. Sin embargo, el análisis de las pernoctaciones revela que el máximo se da indudablemente durante el verano, cuando la estancia media es mucho mayor. Son agosto y, con un periodo de estancia menor, julio, los meses que registran mayor demanda. Esto, obviamente, tiene repercusiones sobre el grado de ocupación (tabla 6) que muestra la misma estacionalidad del turismo litoral.

TABLA 6. Oferta de alojamientos de turismo rural y grado de ocupación por meses, 2001-2002.

\begin{tabular}{|c|c|c|c|c|c|c|}
\hline & \multicolumn{3}{|c|}{ Oferta de alojamiento (camas) } & \multicolumn{3}{|c|}{ Grado de ocupación (\%) } \\
\hline Mes & 2001 & 2002 & $\begin{array}{l}\text { \% variación } \\
2001-2\end{array}$ & 2001 & 2002 & $\begin{array}{l}\text { \% variación } \\
2001-2\end{array}$ \\
\hline Enero & 4.547 & 5.049 & 11,04 & 12,48 & 10,17 & $-2,31$ \\
\hline Febrero & 4.691 & 5.191 & 10,66 & 14,59 & 12,76 & $-1,83$ \\
\hline Marzo & 4.824 & 5.397 & 11,88 & 12,27 & 24,01 & 11,74 \\
\hline Abril & 5.482 & 6.023 & 9,87 & 29,65 & 12,91 & $-16,74$ \\
\hline Mayo & 5.349 & 5.979 & 11,78 & 10,70 & 14,87 & 4,17 \\
\hline Junio & 5.420 & 6.025 & 11,16 & 18,52 & 16,72 & $-1,80$ \\
\hline Julio & 5.477 & 6.142 & 12,14 & 38,82 & 34,88 & $-3,94$ \\
\hline Agosto & 5.533 & 6.286 & 13,61 & 62,69 & 66,24 & 3,55 \\
\hline Septiembre & 5.400 & 5.970 & 10,56 & 24,88 & 23,24 & $-1,64$ \\
\hline Octubre & 5.339 & 6.086 & 13,99 & 17,52 & 13,81 & $-3,71$ \\
\hline Noviembre & 5.201 & 5.803 & 11,57 & 14,47 & 13,05 & $-1,42$ \\
\hline Diciembre & 5.077 & 6.018 & 18,53 & 25,54 & 24,51 & $-1,03$ \\
\hline Media Cataluña & & 24,01 & 22,74 & $-1,27$ \\
\hline Media España & & & & 23,08 & 21,75 & $-1,33$ \\
\hline
\end{tabular}

Fuente: INE (2003a; 2003b).

A partir de los datos de nuestra encuesta constatamos que la ocupación de los establecimientos varía considerablemente. Como resultado, un 35\% de los establecimientos están ocupados entre 61 y 100 días por año, un $29 \%$ lo están entre 101 y 200 y sólo un $4 \%$ están por encima de los 200 días de ocupación; mientras que el $28 \%$ restante está ocupado menos de 61 días por año (gráfico 4).

De hecho, si se suman los meses estivales, fines de semana y otros periodos vacacionales tradicionales (Semana Santa, Navidad y año nuevo, puentes festivos), nos encontramos con un total de entre 160 y 200 días de ocupación, que es una cifra considerable. A la vista de esta realidad y considerando que por ahora este tipo de turismo es un complemento de otras rentas, podemos afirmar que el rendimiento es bueno y el turismo rural en Cataluña está cumpliendo su función.

La demanda relativa parece, no obstante, haber disminuido en el período que va entre el 2001 y el 2002, a juzgar por el descenso del 1,27\% de los niveles de ocupación, que coinciden con los relativos al total español (tabla 7). Un examen más a fondo del grado de ocupación por meses muestra que este descenso se concentró en los meses de julio y octubre. Esta tasa muestra una preocupante tendencia hacia fluctuaciones estacionales más marcadas. No obstante, debemos ser prudentes a la hora de interpretar estos datos, 
ya que el incremento del número de camas acaecido durante el mismo periodo fue mayor que el descenso en los niveles de ocupación. Sin embargo, esta constatación constituye una advertencia y, a nuestro parecer, se deben tomar medidas para asegurar que en el futuro el incremento de la oferta no sea superior a la potencial demanda que tiene este turismo.

El análisis de la estancia indica - como es lógico - que la duración de la estancia media es más elevada para los extranjeros (4,57 días) que para los españoles (2,82 días) (tabla 7). Entre los extranjeros, los belgas (6,53 días) y los estadounidenses $(5,45$ días) son los que permanecen más tiempo (tabla 8). Por otro lado, los turistas españoles de regiones distantes

GRÁFICO 4. Ocupación anual de los establecimientos de turismo rural catalanes, 2002-2003.

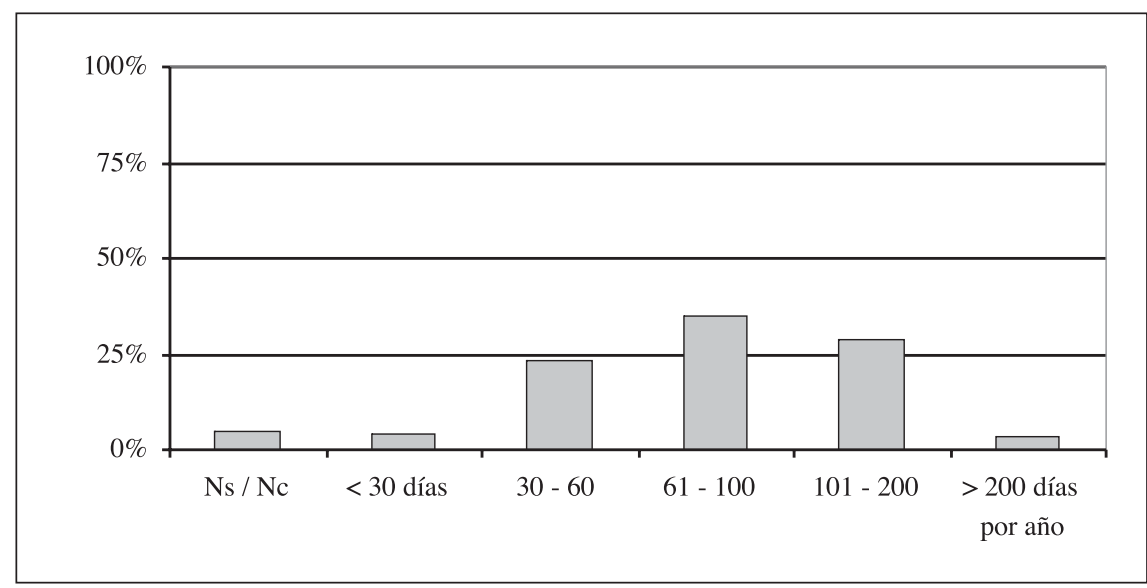

Fuente: Encuestas realizadas. Elaboración propia.

TABLA 7. Duración de la estancia media de Españoles y extranjeros por meses, 2001-2002.

\begin{tabular}{|l|l|l|l|l|l|l|}
\hline \multirow{2}{*}{ Mes } & \multicolumn{3}{l}{ Media global } & \multicolumn{2}{l|}{ Españoles } & \multicolumn{2}{l|}{ Extranjeros } \\
\cline { 2 - 7 } & $\mathbf{2 0 0 1}$ & $\mathbf{2 0 0 2}$ & $\mathbf{2 0 0 1}$ & $\mathbf{2 0 0 2}$ & $\mathbf{2 0 0 1}$ & $\mathbf{2 0 0 2}$ \\
\hline Enero & 2,46 & 2,10 & 2,40 & 2,05 & 3,90 & 4,34 \\
\hline Febrero & 2,03 & 1,92 & 2,00 & 1,89 & $\mathbf{6 , 0 0}$ & 3,75 \\
\hline Marzo & 1,81 & 2,72 & 1,82 & 2,71 & 1,71 & 3,13 \\
\hline Abril & $\mathbf{3 , 2 8}$ & 2,03 & $\mathbf{3 , 2 4}$ & 1,88 & $\mathbf{4 , 4 7}$ & 2,96 \\
\hline Mayo & 1,95 & 2,18 & 1,90 & 2,10 & 2,55 & 2,87 \\
\hline Junio & 2,30 & 2,16 & 2,15 & 1,96 & 3,31 & 3,92 \\
\hline Julio & $\mathbf{4 , 1 9}$ & $\mathbf{3 , 9 1}$ & $\mathbf{3 , 4 5}$ & $\mathbf{3 , 5 3}$ & $\mathbf{7 , 2 1}$ & $\mathbf{5 , 2 3}$ \\
\hline Agosto & $\mathbf{5 , 5 5}$ & $\mathbf{5 , 7 0}$ & $\mathbf{5 , 4 9}$ & $\mathbf{5 , 5 1}$ & $\mathbf{5 , 8 9}$ & $\mathbf{6 , 7 5}$ \\
\hline Septiembre & $\mathbf{3 , 1 2}$ & $\mathbf{3 , 0 6}$ & $\mathbf{3 , 0 7}$ & $\mathbf{2 , 9 2}$ & 3,47 & 3,93 \\
\hline Octubre & 2,02 & 1,78 & 1,93 & 1,78 & 3,86 & 1,92 \\
\hline Noviembre & 2,30 & 2,10 & 2,29 & 2,11 & $\mathbf{1 0 , 7 2}$ & 1,69 \\
\hline Diciembre & 2,85 & $\mathbf{3 , 1 2}$ & 2,84 & $\mathbf{3 , 1 0}$ & 3,24 & $\mathbf{4 , 6 0}$ \\
\hline Media en Cataluña & $\mathbf{3 , 0 5}$ & $\mathbf{2 , 9 9}$ & $\mathbf{2 , 8 8}$ & $\mathbf{2 , 8 2}$ & $\mathbf{4 , 9 8}$ & $\mathbf{4 , 5 7}$ \\
\hline Media en España & $\mathbf{3 , 0 2}$ & $\mathbf{3 , 0 0}$ & & & & \\
\hline
\end{tabular}

Fuente: INE (2003a; 2003b). 
TABLA 8. Duración de la estancia media de los turistas rurales en Cataluña, 2001-2002.

\begin{tabular}{|c|c|c|c|c|c|}
\hline \multicolumn{3}{|l|}{ Países extranjeros } & \multicolumn{3}{|c|}{ Comunidades Autónomas Españolas } \\
\hline País & 2001 & 2002 & Comunidad & 2001 & 2002 \\
\hline Media de todos los países & 4,98 & 4,57 & $\begin{array}{l}\text { Media de todas las } \\
\text { comunidades }\end{array}$ & 2,88 & 2,82 \\
\hline Unión Europea & 5,00 & 4,60 & Cataluña & 2,77 & 2,71 \\
\hline - Bélgica & 7,25 & $\mathbf{6 , 5 3}$ & Andalucía & 5,21 & 4,18 \\
\hline - Holanda & 5,77 & 4,72 & Aragón & 3,38 & 2,92 \\
\hline - Alemania & 4,90 & 4,64 & Asturias & 3,70 & 3,81 \\
\hline - Francia & 4,67 & 4,06 & Islas Baleares & 3,36 & 3,06 \\
\hline - Reino Unido & 4,53 & 4,54 & País Vasco & 2,81 & 3,89 \\
\hline USA & 6,76 & 5,45 & Islas Canarias & 4,00 & 6,82 \\
\hline Otros países & 4,16 & 3,99 & Cantabria & 1,80 & 5,64 \\
\hline & & & Castilla-León & 4,40 & 3,12 \\
\hline & & & Castilla-La Mancha & 3,20 & 2,44 \\
\hline & & & Extremadura & 2,88 & 3,39 \\
\hline & & & Galicia & 2,30 & 5,15 \\
\hline & & & La Rioja & 2,36 & 4,62 \\
\hline & & & Madrid & 4,01 & 3,93 \\
\hline & & & Murcia & 7,07 & 4,32 \\
\hline & & & Navarra & 1,96 & 4,23 \\
\hline & & & Valencia & 3,76 & 4,04 \\
\hline
\end{tabular}

Fuente: INE (2003a; 2003b).

realizan, de hecho, estancias tan largas como las de los extranjeros. De este modo, la estancia media de los turistas procedentes de las Islas Canarias, Cantabria y Galicia es de 6,8, 5,6 y 5,1 días respectivamente. Sin embargo, hay que considerar que actualmente el número de turistas de estas regiones es insignificante tanto en términos absolutos como relativos. En este sentido, son los turistas madrileños los que contribuyen de una forma más significativa, con una estancia media de 4,16 días que les permite generar un 4,76\% del total de las pernoctaciones de los españoles.

Por lo tanto, en el patrón de comportamiento de la demanda predominan las estancias cortas a lo largo de todo el año. Se trata de turistas que no invierten más de dos o tres horas en llegar a su destino. Por otro lado, el mercado tradicional de vacaciones de verano atrae turistas de largas distancias, de diversas procedencias y, lógicamente, con estancias de mayor duración. En definitiva la principal demanda del turismo rural en Cataluña es el mercado local próximo al foco emisor de Barcelona, con un predominio claro de las estancias de dos días y concentración en los meses de verano. A la vista de estos resultados, el turismo rural en Cataluña debe plantearse una mayor diversificación de la oferta, conseguir una menor estacionalidad y una ampliación del origen de los visitantes (Francès.2003,: 1724; Cànoves, et al, 2004: 111-128)

\section{Factores condicionantes}

\subsection{Factores que afectan a la localización}

Tras identificar la distribución de los alojamientos, las características de la demanda y el comportamiento estacional de la misma, veremos los factores que condicionan la 
localización de los establecimientos. Uno de los factores destacados es la capacidad de cada zona de ser atractiva para este tipo de turismo. Es de decir, la potencialidad turística para ofrecer un producto de turismo rural. En este gran ámbito, se consideran entre otros, el paisaje, la oportunidad de practicar deportes de invierno, la capacidad de acogida de los lugares, las edificaciones, el patrimonio arquitectónico, arqueológico, histórico o cultural, la proximidad a la franja marítima, y la accesibilidad del lugar. De acuerdo con lo expuesto, a partir de la encuesta realizada a propietarios y usuarios, junto con el material de las entrevistas en profundidad, es posible establecer relaciones entre los diversos factores y su grado de influencia sobre la demanda. Estos datos nos permiten identificar los factores que destacan los usuarios de turismo rural y ajustar mejor oferta y demanda del sector.

El 95\% de los clientes de turismo rural viajan en coche y constatamos que la distancia de las casas de turismo rural a los principales atractivos de las zonas es inferior a $25 \mathrm{~km}$. (no más de 30 minutos conduciendo). Este hecho nos lleva a pensar que la mayoría de los establecimientos se encuentran dentro de un área apropiada para la movilidad del turista. De hecho, el $77 \%$ de los establecimientos se encuentran a menos de $25 \mathrm{~km}$. de un Parque Natural o Área Protegida (ZEPA ${ }^{3}$; PEIN ${ }^{4}$, coto de caza, etc.), el $74 \%$ de un paraje con atractivos culturales, el $28 \%$ de una estación de esquí, y el $22 \%$ cercanos a la costa (ver Tabla 10). La proximidad a las áreas de valor natural es un denominador común, 800 (72\%) de los 1107 establecimientos registrados en octubre del 2003 (Generalitat de Cataluña, 2003) estaban situados en municipios que formaban parte del Plan de Espacios de Interés Natural (PEIN). Por lo tanto, podemos afirmar que el patrón de distribución del turismo rural es similar al de las zonas de valor natural (figura 6).

Esta distribución coincide, de hecho, con las zonas más húmedas de la comunidad (figura 8), en donde la precipitación anual está por encima de los $600 \mathrm{~mm}$. En las áreas donde prevalecen estas condiciones climáticas, los payeses han sido importantes históricamente, lo que obviamente ha tenido repercusiones positivas sobre la construcción y conservación de casas rurales tradicionales. Además, estas zonas son montañosas, en ellas la vegetación es más exuberante y se considera que su paisaje es el más atractivo para el turismo rural.

TABLA 9. Localización de los establecimientos de turismo rural en relación a los atractivos escogidos.

\begin{tabular}{|l|l|l|l|l|}
\hline \multirow{2}{*}{ Localización } & \multicolumn{3}{|c|}{ Atractivo (\% del total) } \\
\cline { 2 - 5 } & $\begin{array}{l}\text { Parque Natural / } \\
\text { Área Protegida }\end{array}$ & Costa & $\begin{array}{l}\text { Posibilidad de } \\
\text { practicar deportes de } \\
\text { invierno }\end{array}$ & Cultural / Urbano \\
\hline $\mathbf{E n}$ & 22,26 & 1,09 & 4,74 & 10,58 \\
\hline $\mathbf{< 5 ~} \mathbf{~ k m}$ & 19,71 & 5,11 & 1,09 & 15,33 \\
\hline $\mathbf{5 - 1 0} \mathbf{~ k m}$ & 12,41 & 4,01 & 6,20 & 17,15 \\
\hline $\mathbf{1 1 - 2 5} \mathbf{~ k m}$ & 22,63 & 11,68 & 16,06 & 31,02 \\
\hline $\mathbf{2 5} \mathbf{~ k m s}$ & 14,23 & 72,26 & 64,96 & 17,88 \\
\hline $\mathbf{N c} / \mathbf{N s}$ & 8,76 & 5,84 & 6,93 & 8,03 \\
\hline
\end{tabular}

Fuente: Trabajo de campo. Elaboración propia.

3 Zona de Especial Protección para las Aves.

4 Pla d'Espais d'Interés Natural (Plan de Espacios de Interés Natural). 
FIgURA 6. Áreas PEIN (Plan de Espacios de Interés Natural) i municipios que cuentan con estaciones de esquí.

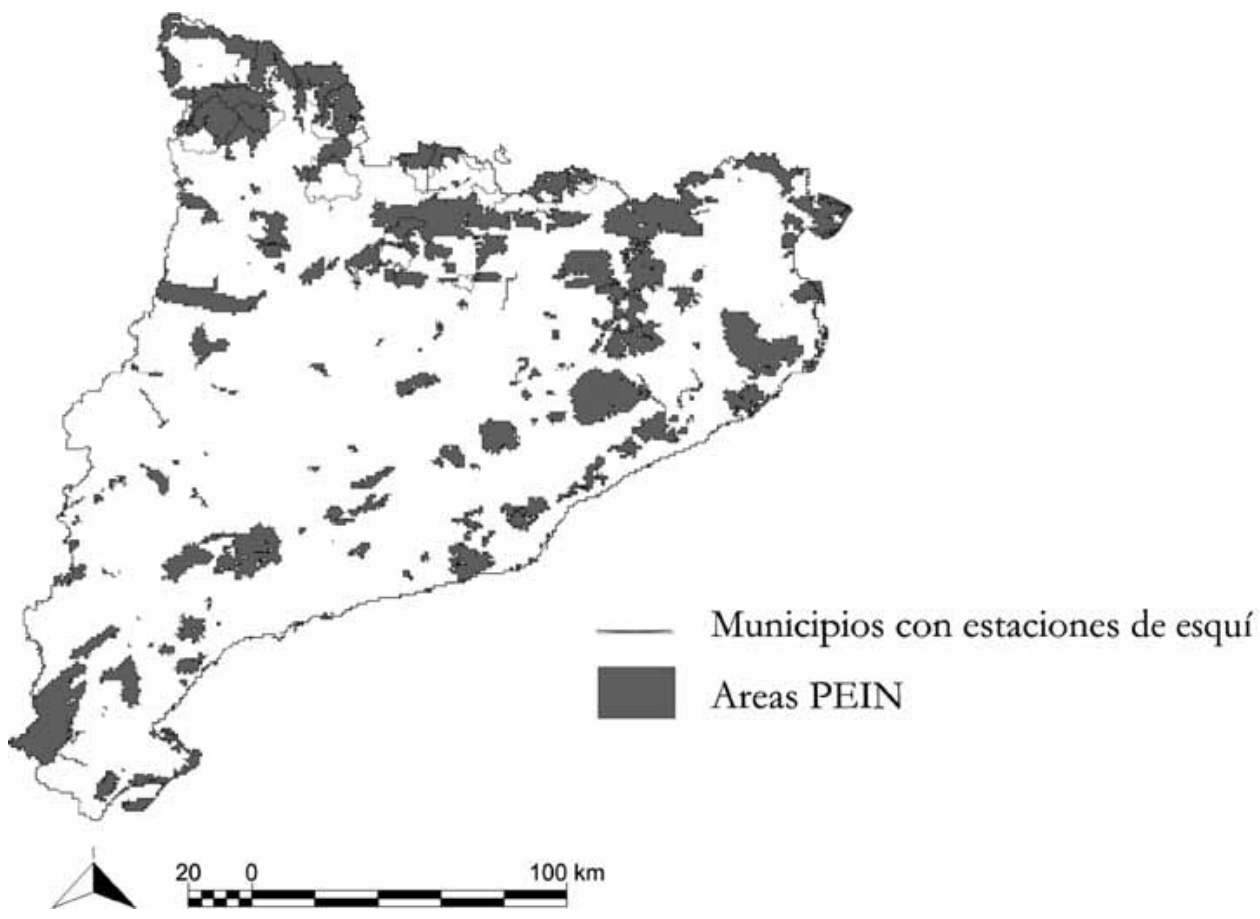

Fuente: Departament de Medi Ambient, 2004.

El desarrollo del turismo rural en estas áreas es, por lo tanto, perfectamente comprensible y coincide con el mayor número de establecimientos (Cànoves et al., 2002: 69-78). En el cuestionario que se administró a los usuarios, el contacto directo con la naturaleza y el paisaje era valorado con una media de 4.5 puntos sobre una escala de 5 . Asimismo, la paz y la tranquilidad del lugar tenía una puntuación similar. Estos resultados tienden a reforzar la idea de la existencia de vínculos entre el turismo rural y el denominado «turismo verde». De un modo similar, el hecho de que dos tercios de los establecimientos estén localizados lejos de la línea de costa refuerza el concepto de turismo rural como un «turismo de interior».

Por otro lado, el espectacular paisaje de la zona de los Pirineos, donde se han ubicado diversas instalaciones de deportes de invierno durante los últimos veinte años, es un aspecto adicional muy importante para los establecimientos de turismo rural de estas áreas. La Tabla 10, muestra la proximidad de los establecimientos de turismo rural a los recursos que pueden ser clasificados como atractivos del «turismo cultural», en especial, los elementos del patrimonio histórico que rodean los diferentes pueblos y aldeas. Entre ellos destacan: Taüll, Vall de Boí, Besalú, Bescaran, Berga, Olot, Girona, Figueres, L’Escala, Empúries, Cardona, Montserrat, Solsona, La Seu d'Urgell y Ripoll, entre otros (Cànoves y Priestley, 2003: 35-48). 
FIGURA 7. Mapa pluviométrico, 2003.

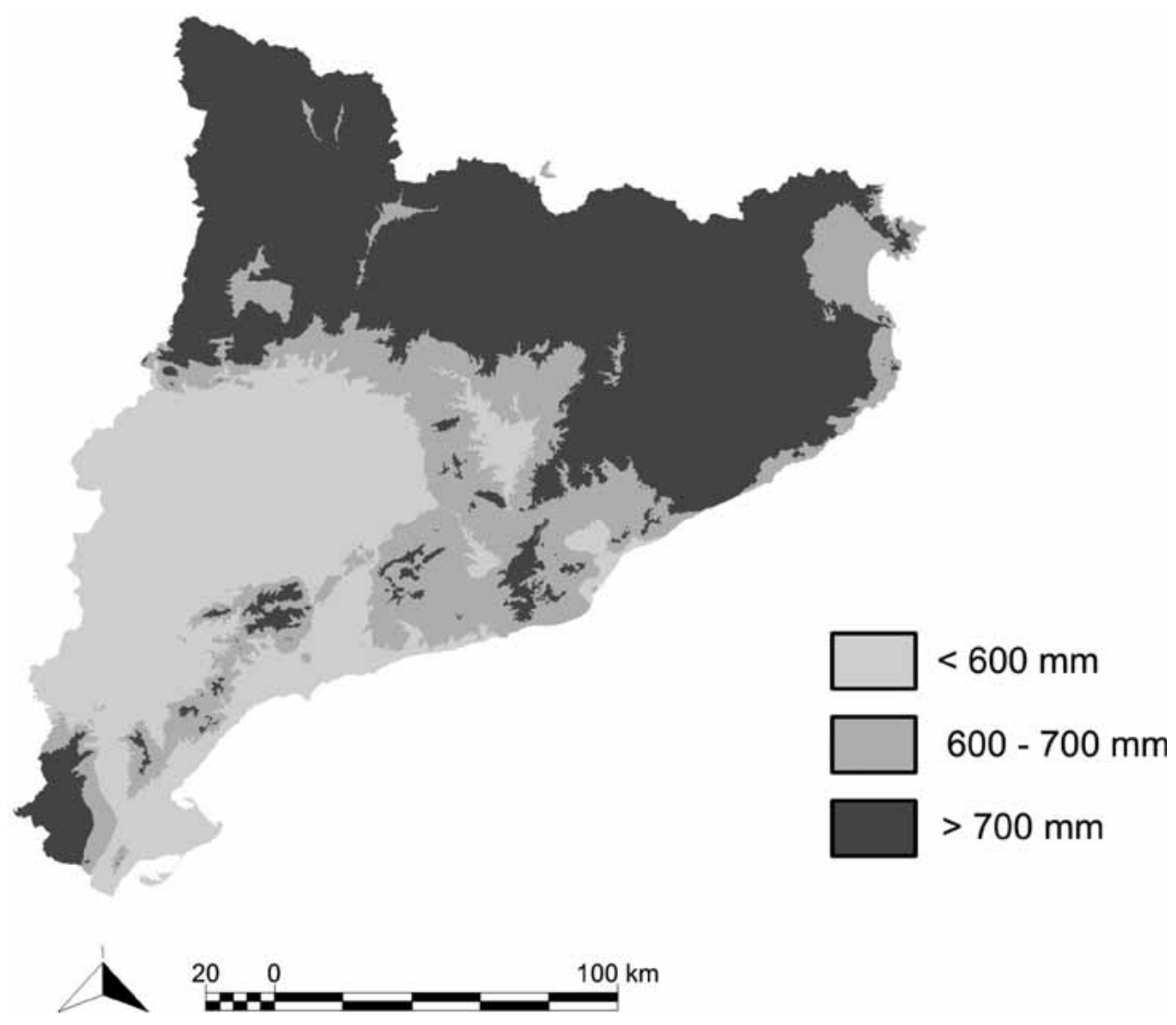

Fuente: Departament de Medi Ambient, 2004.

El municipio de la Vall de Boí dispone de un amplio abanico de atractivos: naturales (Parc Nacional d'Aigüestortes-Estany de Sant Maurici), históricos (Arquitectura y arte románico); deportes de invierno (las áreas de Boi Taüll y Baqueira Beret). Como resultado, existen 46 establecimientos de turismo rural en el municipio y, aunque se trata de uno de los cinco más grandes de Cataluña, este hecho indica el importante papel que juegan los atractivos en el desarrollo de este sector. Aproximándose en importancia numérica existen tres municipios que tienen entre 15 y 20 establecimientos: Alins en el Pallars Sobirà, que ofrece espectaculares paisajes y deportes de invierno; la Vall de Bianya en La Garrotxa, una región volcánica única; y Deltebre en el Baix Ebre, una región especial por su paisaje deltaico.

Sin embargo, existen dos áreas que carecen de establecimientos rurales. La ausencia de estos establecimientos en el área de influencia de la Región Metropolitana de Barcelona ha sido previamente mencionada y explicada. La segunda, la Plana de Lleida, se caracteriza por una gran producción agrícola de carácter intensivo que genera empleo en las áreas rura- 
les y produce considerables beneficios económicos a sus propietarios. El paisaje de esta zona es llano, el clima es relativamente seco y existen amplias zonas de escasa masa forestal. Como resultado, el paisaje es menos atractivo que el de las montañas boscosas y los valles de de la zona del Priorat y las zonas húmedas situadas más al norte. La combinación de estos factores - económicos y naturales - ha sido fundamental para desalentar a los propietarios en la ubicación de establecimientos de turismo rural en esta área.

\subsection{Influencias sobre la demanda}

La influencia de los diversos factores estudiados afecta a la demanda total y al patrón de la demanda. Es imposible hacer un análisis de las estadísticas oficiales para sustentar esta afirmación. Sin embargo el trabajo de campo realizado nos muestra las siguientes consideraciones. La demanda varia según el tipo de alojamiento. Así, vemos que la duración de la estancia tiende a ser más prolongada en los ARIs que en otras tipologías. Factores económicos explican este hecho, los ARIs son sustancialmente más económicos (para grupos de cuatro o más personas) que el resto de tipologías, y por consiguiente, son más demandados para las vacaciones de grupos de amigos o familias.

Los niveles de ocupación también varían en función de la localización del alojamiento y los diversos atractivos que ofrece el lugar. El factor más significativo es, quizás, la oportunidad de practicar deportes de invierno en las zonas montañosas que, se pueden complementar con la demanda que también experimentan durante el periodo estival. Este hecho permite que estas zonas puedan tener dos periodos de temporada alta. Uno invernal y uno estival. Esta mayor demanda permite una mayor ocupación a lo largo del año y por tanto un mejor rendimiento del establecimiento. Resulta sorprendente, sin embargo, que el patrón de la demanda en establecimientos que se encuentran relativamente cercanos a la costa parece situarse en el otro extremo del espectro. Los picos de demanda se registran en el periodo estival, siendo agosto y julio los meses de mayor concentración, obviamente relacionados con la oferta de sol y playa, pero con establecimientos alejados del bullicio del litoral. En contraposición, la demanda es escasa durante el resto del año, un hecho que parece indicar la preferencia de los turistas rurales por las zonas de interior y los paisajes montañosos.

La distancia a Barcelona es también un factor a tener en cuenta a la hora de analizar la demanda (figura 5). Como ya hemos indicado, las áreas rurales se encuentran como máximo a cuatro horas de Barcelona, lo que implica que los establecimientos de turismo rural se pueden beneficiar de la oferta de fin de semana. Las diferencias en el comportamiento de la demanda durante los diferentes momentos del año, son resultado del poder de atracción del patrimonio de cada zona o de la localización del establecimiento. Sin embargo, hay diferencias entre los turistas extranjeros y nacionales, y los locales (catalanes). Para los nacionales y extranjeros la demanda es mayor en el área que se encuentra a menos de una hora de distancia de Barcelona. Es su caso, poderse alojar en el campo y visitar diferentes zonas e incluso desplazarse a Barcelona o Gerona, es un atractivo más. En cambio, los habitantes del área metropolitana de Barcelona tienden a considerar que a una hora de desplazamiento no merece la pena pasar la noche fuera y por lo tanto prefieren regresar a casa. Esta percepción tiene obviamente repercusiones sobre el nivel de ocupación de las casas situadas a poca distancia de Barcelona, que han de promocionarse hacia una demanda menos local y durante los periodos de mayor afluencia de turistas. Sin embargo en estos alojamientos más próximos a Barcelona las estancias de los turistas suelen ser de mayor duración. 


\section{Comparación con el mercado del turismo de sol y playa}

El turismo rural al igual que otros turismos presenta estacionalidad. Es por ello interesante identificar y analizar las similitudes entre el comportamiento de los turistas rurales y los turistas de sol y playa.

Ciertamente, mientras que la oferta del turismo rural $(0.7 \%)$, y, por consiguiente, la demanda $(0.32 \%)$, es insignificante en comparación con la de otros tipos de alojamiento (gráfico 6 y tabla 10), los patrones de la demanda son comparables. Además, hemos constatado que el usuario en algunas ocasiones opta por hoteles, apartamentos turísticos y, en otras por alojarse en establecimientos de turismo rural.

Los alojamientos de turismo rural, como se ha comentado previamente, constituyen un $0.7 \%$ del total de establecimientos, pero significan únicamente un $0.32 \%$ de la demanda. Esto indica que la duración de la estancia de los turistas rurales es menor que en el resto de sectores. Mientras que para el turismo rural la estancia se sitúa en torno a los 3 días, la media global lo hace en torno a los 6.7 (INE, 2003b).

La demanda del turismo rural se incrementó con mayor rapidez que la hotelera entre el 2001 y el 2002 (Tabla 11), pero este dato ha de ser interpretado con extrema precaución por dos motivos. En primer lugar, a pesar de que la demanda de turismo rural parece estar incrementándose, un periodo de dos años es insuficiente para mostrar una tendencia clara, especialmente en el año inmediatamente posterior a los ataques del 11 de Septiembre en Nueva York. En segundo lugar, dado que los valores absolutos para ambos tipos de alojamiento están muy alejados (siendo los datos referidos al sector hotelero sustancialmente mayores), pequeños incrementos en la demanda de turismo rural aparecen como un incremento porcentual superior al de incrementos numéricos mayores para el sector hotelero. Sin embargo, estos datos muestran que el turismo rural todavía depende de la demanda nacional y que la demanda extranjera penetra con lentitud.

TABLA 10. Oferta hotelera y grado de ocupación mensual, 2001-2002.

\begin{tabular}{|l|l|l|l|l|l|l|}
\hline \multirow{2}{*}{ Mes } & \multicolumn{2}{|l|}{ Oferta de alojamiento (camas) } & \multicolumn{3}{l|}{ Grado de ocupación (\%) } \\
\cline { 2 - 7 } & $\mathbf{2 0 0 1}$ & $\mathbf{2 0 0 2}$ & $\begin{array}{l}\text { \% variación } \\
\mathbf{2 0 0 1 - 2}\end{array}$ & $\mathbf{2 0 0 1}$ & $\mathbf{2 0 0 2}$ & $\begin{array}{l}\text { \% variació } \\
\mathbf{2 0 0 1 - 2}\end{array}$ \\
\hline Enero & 97.387 & 100.807 & 3,51 & 37,23 & 34,61 & $-2,62$ \\
\hline Febrero & 103.727 & 106.757 & 2,92 & 45,68 & 44,18 & $-1,50$ \\
\hline Marzo & 113.515 & 122.637 & 8,04 & 45,53 & 51,10 & 5,57 \\
\hline Abril & 169.526 & 171.087 & 0,92 & 54,08 & 49,41 & $-4,67$ \\
\hline Mayo & 201.416 & 210.430 & 4,48 & 51,75 & 54,78 & 3,03 \\
\hline Junio & 219.429 & 230.128 & 4,88 & $\mathbf{6 2 , 7 9}$ & $\mathbf{5 8 , 7 6}$ & $-4,03$ \\
\hline Julio & 236.407 & 242.725 & 2,67 & $\mathbf{7 4 , 3 2}$ & $\mathbf{7 1 , 2 3}$ & $-3,09$ \\
\hline Agosto & 237.663 & 243.599 & 2,50 & $\mathbf{8 0 , 7 5}$ & $\mathbf{7 8 , 3 8}$ & $-2,37$ \\
\hline Septiembre & 232.014 & 233.071 & 0,46 & $\mathbf{6 7 , 8 2}$ & $\mathbf{6 2 , 6 9}$ & $-5,13$ \\
\hline Octubre & 171.580 & 177.499 & 3,45 & 53,16 & 56,30 & 3,14 \\
\hline Noviembre & 103.275 & 107.016 & 3,62 & 43,71 & 43,26 & $-0,45$ \\
\hline Diciembre & 103.124 & 113.134 & 9,71 & 36,89 & 36,28 & $-0,61$ \\
\hline Media de Cataluña & & & & 58,74 & 57,16 & $-1,58$ \\
\hline Media de España & & & & 58,06 & 55,27 & $-2,79$ \\
\hline
\end{tabular}

Fuente: INE (2003a; 2003b). 
TABLA 11. Incremento de la demanda de los establecimientos de turismo rural y hoteleros, 2001-2002.

\begin{tabular}{|l|c|c|c|c|}
\hline \multirow{2}{*}{$\begin{array}{c}\text { Procedencia de } \\
\text { los visitantes }\end{array}$} & \multicolumn{2}{|c|}{ Establecimientos de Turismo Rural } & \multicolumn{2}{c|}{ Hoteles } \\
\cline { 2 - 5 } & \% Visitantes & \% Pernoctaciones & \%Visitantes & $\begin{array}{c}\text { \% } \\
\text { Pernoctaciones }\end{array}$ \\
\hline Total & 8.89 & 6.60 & 3.21 & 0.22 \\
\hline Españoles & 6.80 & 4.55 & 0.11 & -0.84 \\
\hline Extranjeros & 2.10 & 2.04 & 3.10 & 1.06 \\
\hline
\end{tabular}

Fuente: INE (2003).

Una de las principales diferencias en la demanda es la proporción de extranjeros. Como ya se ha indicado, en el 2002 un $90 \%$ de los turistas rurales en Cataluña eran españoles, mientras que en los hoteles un $45 \%$ eran españoles y un 55\% extranjeros. Todavía más significativa es la dependencia del turismo rural respecto al mercado local catalán. Los países de origen de los extranjeros son similares, pero los visitantes de Italia, Suiza, los países nórdicos y Japón, con una presencia notable en el total de las tipologías, no se encuentran en el turismo rural. El turismo rural catalán puede ser potenciado en el mercado europeo, mientras que el japonés, por ahora, es una opción menos realista, ya que los japoneses se sienten atraídos por la bien conocida arquitectura barcelonesa.

El grado de ocupación de los establecimientos de turismo rural es notablemente inferior al de otros establecimientos (gráfico 5 y tablas 6 y 10).

La media anual para hoteles se sitúa entorno al 55\% y para el mes de menor ocupación (enero) sobre el 35\%. En los establecimientos de turismo rural la ocupación supera el 15\% sólo en verano, diciembre y el mes que incluya las vacaciones de Semana Santa. No obstante, debemos se cautos al realizar esta comparación, puesto que las estadísticas se basan

GráFICO 5. Grado de ocupación de establecimientos turísticos en Cataluña, 2002.

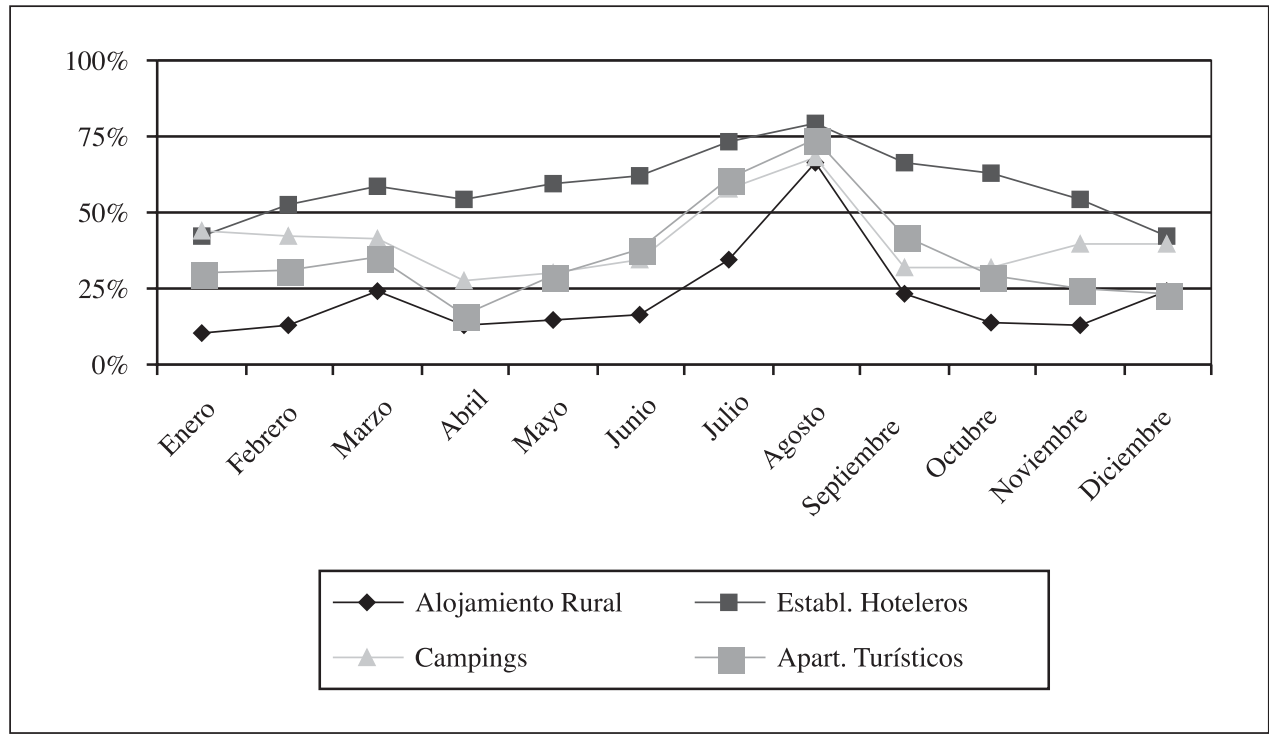

Fuente: ANDRÉ, M.E. (2003: 261-275). Elaboración propia. 
en los establecimientos disponibles cada mes (es decir, los establecimientos que están abiertos). De manera que, mientras la mayoría de hoteles, y cada vez más apartamentos y campings, cierran en invierno, únicamente una pequeña proporción de establecimientos de turismo rural cierra durante esta temporada (gráfico 6).

Por otro lado, los establecimientos de turismo rural realizan la actividad turística como un complemento a la actividad agraria y por lo tanto, en la mayoría de los casos, el sector representa unos ingresos complementarios para la mayoría de los propietarios. La ventaja del turismo rural, es que los costes generados cuando las habitaciones no están ocupadas son escasos, en contraposición a otros tipos de establecimientos (como los hoteles) que necesitan una plantilla para ser gestionados. Aún así, se debe reconocer que el grado de ocupación del turismo rural es bajo, situación ciertamente preocupante para la viabilidad de la actividad (Cànoves, et al, 2004: 755-769).

Respecto a la corta duración de la estancia en establecimientos de turismo rural, a la que ya hemos prestado atención anteriormente, los datos relativos al sector hotelero son, de hecho, incluso inferiores (tabla 13) (Dirección General de Turismo, 2004). No obstante, hay una diferencia importante, reflejo de las respectivas causas. La baja media en turismo rural es el resultado de la concentración de la demanda durante los fines de semana y de una escasa o nula ocupación entre semana (excepto en temporada alta). Para los hoteles en general, este es resultado del predominio de hoteles urbanos, donde la demanda está relacionada con viajes de negocios, asistencia a congresos y ferias comerciales, y viajes turísticos de fin de semana; los cuales generan estancias cortas, pero que se extienden a lo largo del año. Los mayores niveles de ocupación asociados a visitantes extranjeros responden a la concentración relativa de la demanda durante las vacaciones de verano en los resorts costeros.

GRÁFICO 6. Proporción de establecimientos abiertos a lo largo del año, 2002*

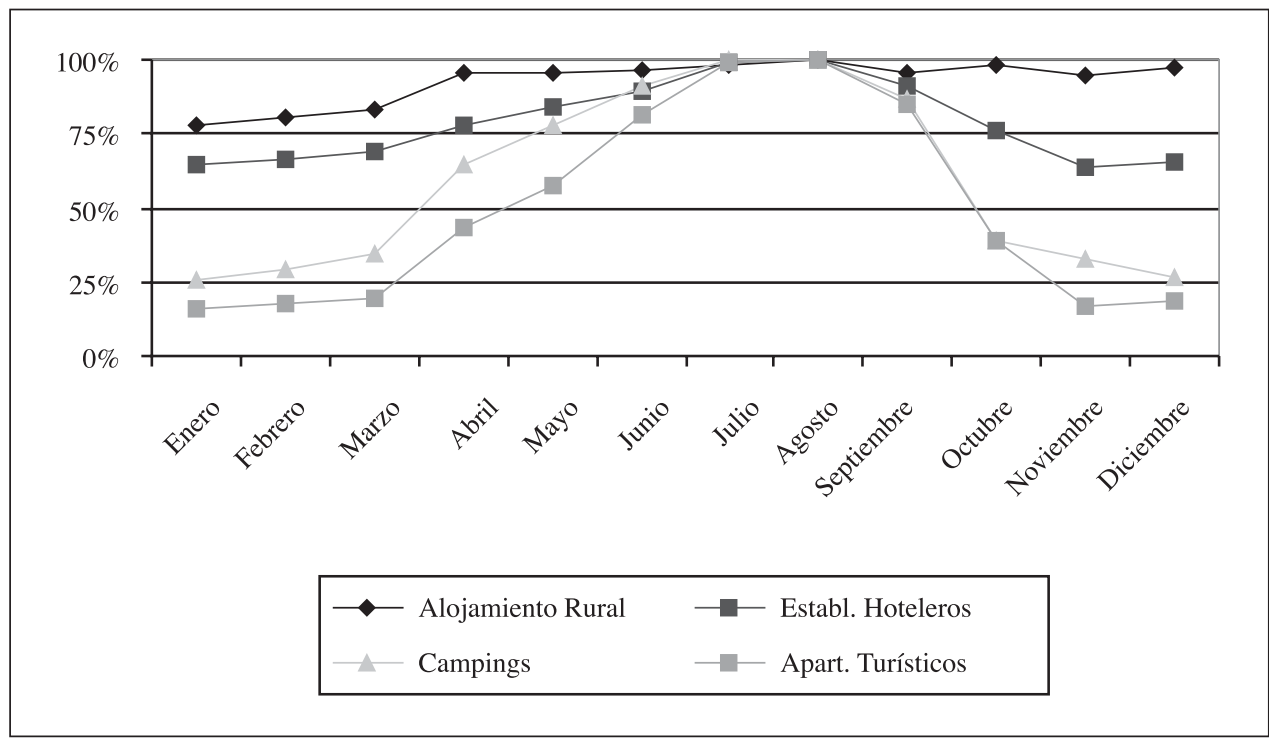

* Se ha supuesto que todos los establecimientos turísticos abrían en agosto.

Fuente: ANDRÉ, M.E. (2003:261-275). Elaboración propia. 
TABLA 12. Estancia media, 2002.

\begin{tabular}{|l|c|c|c|}
\hline Tipo de alojamiento & Españoles & Extranjeros & Total \\
\hline Alojamiento rural & 2,82 & 4,57 & 2,99 \\
\hline Hoteles & 2,6 & 4,1 & 3,5 \\
\hline Campings & 4,91 & 7,76 & 6,20 \\
\hline Apartamentos turísticos & 8,97 & 10,07 & 9,74 \\
\hline
\end{tabular}

Fuente: INE (2003a; 2003b).

Por el contrario, la estancia media en campings y en apartamentos turísticos, que constituyen una parte importante de la oferta total, es mucho mayor (INE, 2003b). Esto se debe fundamentalmente a dos factores: en primer lugar, son más económicos, así que son más los visitantes que los escogen por largos periodos vacacionales, de la misma forma que los turistas rurales permanecen más tiempo en los ARIs que en el resto de tipologías de establecimientos de turismo rural. El segundo factor, es el hecho de que muchos de estos establecimientos sólo abran durante los meses de verano y, por lo tanto, con estancias más largas.

\section{Conclusiones}

Aunque la gran mayoría de establecimientos de turismo rural se encuentra cerca de una amplia variedad de zonas de valor patrimonial y paisajístico,(Cànoves, et al, 2002a : 69-78) debemos ser cautos a la hora de establecer relaciones directas entre la causa (atracción) y el efecto (desarrollo del turismo rural). Ciertamente, la proximidad de potenciales atracciones ha alentado el establecimiento de la oferta, especialmente donde se combinan explotaciones del sector primario con casas de valor patrimonial y paisajes atractivos; que a menudo, se encuentran en áreas naturales protegidas de la Cataluña húmeda.

Sin duda, la oferta no ha alcanzado todavía su límite en Cataluña, ya que la capacidad total es aún baja en valores absolutos y sólo un pequeño porcentaje de los posibles establecimientos se ha puesto en el mercado. Sin embargo, el descenso en los niveles de ocupación que se experimentó entre los años 2001 y 2002 merece especial atención. Este descenso parece indicar un aumento de la demanda inferior al aumento de la oferta, y pone de manifiesto temas relacionados con la capacidad de acogida y los límites potenciales de la demanda. Por supuesto, hemos de ser precavidos a la hora de establecer conclusiones, ya que un período de dos años es insuficiente para definir tendencias. Quizás la demanda generada dentro de la comunidad ha alcanzado su límite. Una reciente encuesta señaló que muchos catalanes que visitan el medio rural con fines recreativos querrían comprar una segunda residencia en éste, así que la demanda del turismo rural podría incluso decrecer. Son necesarias políticas que combatan el excesivo aumento de la segunda residencia, que tantos impactos genera sobre el medio, para evitar este escenario. Por lo tanto, el marketing del producto debe de ser mejorado para atraer el gran potencial de visitantes nacionales y extranjeros, que actualmente se encuentran fuera de los patrones de demanda.

La comparación del patrón de la demanda en hoteles y apartamentos con el de las diferentes formas de alojamiento rural revela muchas similitudes, en aspectos tales como la estancia media, estacionalidad, etc. Merece especial atención el hecho de que la demanda es inferior en aquellos establecimientos rurales cercanos a la costa, que muestran un patrón similar a los de hoteles y resorts costeros. Por lo tanto, sería recomendable para 
estos establecimientos ampliar el rango de atracciones — incluyendo, por ejemplo, aquellas relacionadas con el turismo cultural - en un intento de cambiar su imagen, actualmente asociada al turismo de sol y playa $-\mathrm{y}$, por consiguiente, de aumentar la demanda en temporada baja.

De hecho, la estacionalidad es un problema generalizado para el turismo rural; a pesar de que algunas zonas tengan dos temporadas altas (invierno y verano), la demanda de lunes a viernes (excepto en verano) es muy limitada. La expansión del mercado atrayendo visitantes de fuera de Cataluña - tanto españoles como, sobre todo, extranjeros - se presenta como la mejor opción, pero la difusión y comercialización debe ser ampliamente mejorada para alcanzar el mercado potencial. El turismo rural es una oferta más del mercado turístico y aunque tiene unas claras particularidades, parece que se empieza a comportar como los restantes productos. Sin embargo, por su pequeña dimensión, integración territorial y paisajística, rehabilitación patrimonial y capacidad de retención de población en el medio rural debe continuar considerándose en Cataluña como un proyecto de especial atención y cariño. Las opciones de ocupación en el medio rural para las personas jóvenes y las mujeres son limitadas y el turismo rural ha permitido iniciativas novedosas y de calidad que están teniendo muy buenos resultados, por ello no debe de dejar de considerarse como un sector estratégico de sostenibilidad social y medioambiental en nuestro maltrecho medio rural.

\section{Bibliografía}

ANDRÉ, M. E. (2003): Cataluña. La actividad turística española en 2002. en Antón, S. y Pulido J.I. (eds). AECID, Madrid, pp. 261-275.

BARKE, M. (2004): «Rural Tourism in Spain» en International Journal of Tourism Research, $\mathrm{n}^{\circ} 6$, pp. 137-149

CÀNOVES, G. y VILLARINO, M. (2000): «Turismo en Espacio rural en España: Actrices e imaginario colectivo», en Documents d' Anàlisi Geográfica, no 37, pp. 51-77.

CÀNOVES, G. y VILLARINO, M. (2002): «Rural Tourism, gender, and cultural conservation in Spain and Portugal», en Gender/Tourism/Fun, Swain MB, Monsen JH, (eds). Cognizant Communication Corporation. New York, pp. 90-103

CÀNOVES, G. et al. (2002a): «El patrimonio paisajístico como producto de consumo del turismo rural: Casuísticas regionales», en Actas del XI coloquio de geografía rural. Universidad de Cantabria, Cantabria, pp. 69-78.

CÀNOVES, G. y PRIESTLEY, G. (2003): «The evolution of rural tourism in Spain», en Journal of Hospitality and Tourism, vol, 1, n 2, pp. 35-48.

CÁNOVES,G., VILLARINO, M., HERRERA, Ll. y CUESTA, L. (2004): «Turismo rural en Cataluña: Algunos problema sin resolver», en Cuadernos Geográficos, vol 34 , pp. 111-128.

CÀNOVES, G. et al. (2004a): «Rural tourism in Spain: an analysis of recent evolution», Geoforum vol, 35 pp. 755-769.

Cataluña. España. Decreto 214/1995, de 27 de junio. Diari Oficial de la Generalitat de Catalunya (DOGC), 7 de agosto de 1995, n 2085, p. 5973.

Cataluña. España. Ley 13/2002, de 21 de junio. Diari Oficial de la Generalitat de Catalunya (DOGC), 29 de noviembre de 1989, n 1225, p. 4520.

Departament de Medi Ambient. Generalitat de Catalunya (2004). Cartografía de referencia. $<\mathrm{http}: / /$ mediambient.gencat.net $>$. (Consultada en enero del 2004)

Direcció General de Turisme (Generalitat de Catalunya). Estadísticas de turismo de Cataluña, 2001 y 2002. <www.gencat.net/turisme>. (Consultada el 14 de febrero del 2004). 
Generalitat de Catalunya (Octubre del 2003). Base de datos de los establecimientos de turismo rural catalanes.

IET (Instituto de Estudios Turísticos). (2004). Estadísticas de turismo de España, 2001 y 2002. <http://www.iet.tourspain.es>. (Consultada el 14 de febrero del 2004).

INE (2003a). Encuesta de ocupación en alojamientos de turismo rural, 2001. $<$ http://www.ine.es/inebase, 2001>. (Consultada el 16 de diciembre del 2003).

INE (2003b). Encuesta de ocupación en alojamientos de turismo rural, 2002. $<$ http://www.ine.es/inebase, 2002>. (Consultada el 16 de diciembre del 2003).

FRANCÈS, G. (2003): «Les xarxes de gestió del turisme rural a Catalunya i el seu moviment associatiu», Estudis de Turisme de Catalunya, 13, pp. 17-24

YAGÜE, R.M. (2002): «Rural Tourism in Spain», en Annals of Tourism Research, 29 (4), pp. 1101-1110. 